\title{
A FREQUÊNCIA DE QUESTÕES RELACIONADAS BIOTECNOLOGIA E TECNOLOGIAS DO DNA NO EXAME NACIONAL DO ENSINO MÉDIO (ENEM) E SUA IMPORTÂNCIA NO ENSINO BÁSICO
}

\author{
César Silva Xavier \\ Instituto Federal do Espírito Santo \\ Linhares, Espírito Santo \\ E-mail: cesar.xavier@ifes.edu.br
}

\begin{abstract}
Resumo: O presente artigo corresponde a um estudo qualitativo que analisa a frequência em que temas da Biotecnologia tem sido abordado no Exame Nacional do Ensino Médio (ENEM) e a importância da abordagem destes temas junto aos alunos do ensino básico. O objetivo deste trabalho foi analisar dados das avaliações do ENEM para responder os seguintes questionamentos: "A biotecnologia é um assunto frequentemente contemplado nas avaliações de Biologia? Dentre os assuntos da biotecnologia, quais são os mais abundantemente contemplados?" Foram analisadas as provas de Biologia do caderno amarelo das edições de 2009 a 2015 do ENEM e contabilizados os assuntos relacionados à temas específicos da Biotecnologia e tecnologias do DNA. Por meio desta pesquisa evidenciou-se que dentre os diversos temas da Biologia, o ENEM dedicou o equivalente a $15 \%$ das questões para assuntos relacionados à Biotecnologia. Os temas mais abordados foram tecnologia do DNA recombinante, transgênicos, fluxo gênico, seguido de DNA mitocondrial e eletroforese.
\end{abstract}

Palavras-chave: biotecnologia, tecnologias do DNA, ENEM, ensino de biologia.

FREQUENCY OF QUESTIONS RELATED TO BIOTECHNOLOGY AND DNA TECHNOLOGIES IN BRAZILIAN NATIONAL HIGH SCHOOL EXAMINATION (ENEM) AND ITS IMPORTANCE IN SCHOOL EDUCATION

\begin{abstract}
This article it's a qualitative study for analyzes how often questions Biotechnology has been addressed in the National Secondary Education Examination (ENEM) and the importance of addressing these issues with the students of basic education. The objective of this study was to analyze data from ENEM proof to answer the following questions: "Biotechnology is a subject often contemplated in Biology proof? The issues of biotechnology are abundantly contemplated? The evidence of biology yellow notebook of the 2009 proof were analyzed to 2015 ENEM and accounted for the issues related to specific areas of biotechnology and DNA technologies. Through this research it was shown that among the many topics of biology, the ENEM devoted the equivalent of $15 \%$ of the questions on questions related to biotechnology. The most discussed topics were recombinant DNA technology, transgenic, gene flow, mitochondrial DNA and electrophoresis.
\end{abstract}

Keywords: biotechnology, DNA technology, ENEM, biology teaching.

Recebido em 29/03/2016. Publicado em 31/12/2016. 


\section{INTRODUÇÃO}

O desenvolvimento e inovação de produtos, serviços e tecnologias nas mais diversas áreas da medicina, biotecnologia, tecnologia da informação, transportes e comunicação, perpassando pelas ciências físicas, químicas, biológicas e humanas, avança em um ritmo que na maioria dos casos, grande parte da população é incapaz de acompanhar. Utilizando um olhar mais atento a respeito do tema, pode-se confirmar que o ritmo de inovação do mercado, é ditado pelo avanço da pesquisa e da tecnologia que se desenvolve com o aprimoramento do conhecimento acumulado ao longo de anos de desenvolvimento científico e tecnológico. Para que a população tenha a oportunidade de se utilizar dos produtos, serviços e tecnologias oriundas do desenvolvimento da pesquisa, com consciência e criticidade sobre os riscos e benefícios envolvidos, faz-se necessário que a escola permita o acesso de seus alunos às novidades tecnológicas. Desta forma, torna-se importante e necessário a obtenção do conhecimento desde seus fundamentos para o sucesso na formação de estudantes capacitados ao aprendizado contínuo e a aquisição permanente de informações novas (XAVIER, et al 2005).

Quando dedicamos atenção a Nova Biologia, que inclui os conhecimentos relacionados à Biotecnologia e à Biologia Molecular (LORETO e SEPEL 2003) nos deparamos com uma enxurrada de inovações e novidades. "No limiar do século XXI a biotecnologia é uma realidade que se impõe" (GOULART e MAIA 2012, p. 1). Na medicina podem ser citados, hormônios e outras substâncias obtidas por engenharia genética, vacinas obtidas a partir de OGMs, o arroz dourado, rico em pró vitamina $A$, terapias com células tronco, uso de animais transgênicos para a obtenção de proteínas específicas ou como modelos de experimentação, uso de técnicas como PCR para a identificação e isolamento de patógenos na diagnose de doenças (TERRA et al 2000). A produção de plantas transgênicas como o milho Bt (Bacilus turgiensis), capaz de produzir entomotoxinas que eliminam pragas, plantas resistentes microorganismos como fungos, plantas resistentes a adversidades ambientais como, seca, salinidade (OLIVEIRA, et al 2013), além de plantas resistentes a herbicidas. Na Biologia Forense, a Nova Biologia está presente na identificação de pessoas (AGOSTINHO, et al, 2011), sendo eficiente para elucidação de crimes, identificação de suspeitos, determinação de paternidade, solução de casos de trocas ou desaparecimento de bebes. Estes e outros são exemplos de que a Nova Biologia está cada vez mais presente no nosso dia a dia, sendo explorada nos mais variados setores da indústria e consequentemente atingindo uma grande parcela da população de 
forma direta ou indireta. As aplicações relacionadas às tecnologias do DNA, nas áreas da indústria, agricultura e medicina, certamente esbarram em questões sociais e éticas, sem contar com as implicações ecológicas e sobre a saúde humana, "torna-se necessária uma população que esteja informada sobre os novos avanços no campo da tecnologia genética e que não se sinta socialmente impotente ou insignificante" (REIS, 2003 p. 56).

Noções sobre temas relacionados às novas tecnologias devem ser abordados em diversos momentos ao longo da vida estudantil do jovem, considerando o enfoque e o aprofundamento adequados em cada fase. As inter-relações entre o conhecimento científico a as mudanças tecnológicas devem ser compreendidas principalmente nas últimas séries do ensino fundamental e no ensino médio levando então os jovens a considerarem os "impactos que as tecnologias podem produzir sobre sua qualidade de vida" (BOSSOLAN 2005, et al, p. 41).

As Orientações Educacionais Complementares aos Parâmetros Curriculares Nacionais do PCN+EM sugerem que uma das competências na área das Ciências da Natureza, Matemática e suas Tecnologias é a capacidade de "consultar, analisar e interpretar textos e comunicações de ciência e tecnologia veiculados por diferentes meios" (BRASIL, 2007, p. 36-37). Uma das competências deste grupo com correspondência para a Biologia é, "Avaliar a procedência da fonte de informação para analisar a pertinência e a precisão dos conhecimentos científicos veiculados no rádio, na tevê, nos jornais, nas revistas e nos livros e que se destinam a informar o cidadão ou a induzi-lo ao consumo, principalmente quando se tratar de assuntos relacionados à saúde, como o uso de medicamentos e de alimentos, para distinguir informação fundamentada da simples propaganda (BRASIL, 2007a, p. 37).

Embora a competência correspondente à biologia citada nas orientações educacionais complementares aos PNCs (BRASIL, 2007), seja genérica, é de grande importância que a escola forneça conhecimentos sobre Biotecnologia desde os seus fundamentos, considerando a forma alarmista e pouco elucidativa empregada pela mídia em geral, conforme afirma (GOULART e MAIA 2012). De certa forma fica a cargo da escola, geralmente professores da área de Biologia, o fornecimento de subsídios teóricos para que os alunos desenvolvam tais competências críticas na avaliação das fontes e textos relacionados a temas da Biotecnologia. 
De posse dos conhecimentos relacionados ao DNA, síntese protéica, e a influência destes mecanismos sobre as características dos seres vivos. Com capacidade para relacionar tais conhecimentos com a genética mendeliana e outros temas da genética clássica, o aluno terá melhores condições para compreender os conceitos relacionados com assuntos inerentes à Biotecnologia como clonagem, engenharia genética e outros assuntos associados às tecnologias de manipulação do DNA, desta forma desenvolvendo um posicionamento crítico sobre as questões éticas, morais, políticas e econômicas acerca dos avanços científicos e tecnológicos desta área. Pode-se considerar que o Ensino Médio "é um momento bastante propício ao trabalho com a superação de posturas que, por omitir a real complexidade das questões, induz a julgamentos simplistas e, não raro, preconceituosos" (BRASIL, 2000, p. 19).

Confirmando a importância dada aos temas relacionados à Biotecnologia no Ensino Médio, este conteúdo vem sendo contemplado no Exame Nacional do Ensino Médio (ENEM) e nos principais vestibulares do país.

O ENEM foi criado em 1998 o objetivo de avaliar o desempenho de alunos concluintes do ensino básico, atuando como um mecanismo de aferição das habilidades e competências adquiridas pelos alunos, necessárias ao pleno exercício da cidadania (ANDRIOLA, 2011). Inicialmente com discreta adesão dos alunos concluintes do ensino básico, contou em 1998 com 115.600 inscritos, alcançando o equivalente a 4.600.000 inscritos em 2010. Em 2004, o ENEM passa a ser utilizado como critério para a obtenção de bolsas pelos alunos que pretendem concorrer ao Programa Universidade para Todos (Prouni) e ao menos 539 Instituições de Ensino Superior (IES) passam a adotar os resultados da prova como critério de classificação dos candidatos para o ingresso nos cursos superiores, substituindo de certa forma a seleção de alunos através do vestibular. Até 2008, a prova do ENEM era constituída por 63 questões interdisciplinares, nem sempre com articulação com o que era visto no Ensino Médio. Também até 2008 não havia mecanismos para que o aluno pudesse comparar os seus resultados com os anos anteriores. A partir de 2009 com a implementação do Novo ENEM, as disciplinas passaram a serem distribuídas por área de conhecimento sendo, Linguagens, códigos e suas tecnologias, Ciências Humanas e suas tecnologias, Ciências da Natureza e suas tecnologias e Matemática e suas tecnologias, a prova passou a constar de 45 questões de cada um desses grupos, totalizando 180 questões mais a redação em português, distribuídas em duas provas aplicadas em 
dois dias. Além do que foi descrito, a partir de 2009, os alunos tiveram a possibilidade de comparar seu desempenho nas provas do ENEM ao longo dos anos (ANDRIOLA, 2011).

Embora a importância do ensino de Biotecnologia no ensino médio não se resuma ao fato de que estes conteúdos têm sido efetivamente contemplados no ENEM, ou em exames para admissão nos cursos superiores, não se deve negar que "o ENEM nasce visando ser um instrumento governamental para forçar um currículo de base nacional, testando a qualidade da educação via o instrumento avaliativo sendo, assim, reguladora da qualidade" (SANTOS, J., 2011, p. 195). Considerando uma função mais profunda e não apenas uma avaliação da qualidade do ensino, o ENEM “tende a vincular o conhecimento, expresso nas competências e habilidades, ao que é entendido como necessário ao indivíduo em toda sua vida" (LOPES e LÓPEZ, 2010, p. 103).

A matriz de referência do ENEM apresenta uma sessão com os objetos de conhecimento relacionados. Sobre a Biotecnologia temos que o aluno deverá apresentar:

Noções sobre células-tronco, clonagem e tecnologia do DNA recombinante. Aplicações de biotecnologia na produção de alimentos, fármacos e componentes biológicos. Aplicações de tecnologias relacionadas ao DNA a investigações científicas, determinação da paternidade, investigação criminal e identificação de indivíduos. Aspectos éticos relacionados ao desenvolvimento biotecnológico. Biotecnologia e sustentabilidade (BRASIL, 2009).

A Habilidade 11 contempla a Biotecnologia na Matriz de Referência do ENEM e diz "Reconhecer benefícios, limitações e aspectos éticos da biotecnologia, considerando estruturas e processos biológicos envolvidos em produtos biotecnológicos" (BRASIL, 2009).

O objetivo deste estudo foi analisar qual a frequência em que temas da biotecnologia foram contemplados nas provas do ENEM de 2009 a 2015 e dentre os diversos temas da biotecnologia, quais são mais frequentemente contemplados.

\section{PERCURSO METODOLÓGICO}

O trabalho que segue trata-se de um estudo qualitativo e consistiu em analisar as avaliações da área de conhecimento "Ciências da natureza e suas tecnologias", que inclui as disciplinas de Biologia, Física e Química. Foram analisadas todas as provas do Novo ENEM aplicadas entre 2009 e 2015. 
As 7 provas analisadas foram obtidas a partir do site do Instituto Nacional de Pesquisas Educacionais Anísio Teixeira (INEP), especificamente as provas do caderno amarelo. Não foram analisadas as provas de 1998 a 2008 devido ao fato de apresentarem outro formato e número de questões diferentes do modelo adotado pelo Novo ENEM que ocorreu entre 2009 e 2015.

A análise de conteúdo, iniciou-se com a pesquisa ao site do INEP em busca dos exames das Edições do Novo Enem, nesta etapa as provas foram separadas por data e organizadas em pastas específicas. Na segunda etapa foi feita a leitura das provas com o objetivo de conhecer e organizar o material. Nesta etapa foram selecionados os conteúdos e identificadas as questões de biologia, estabelecendo o contato com os documentos a serem analisados. Uma vez que as questões de biologia foram identificadas, iniciou-se a terceira etapa consistiu em selecionar sistematicamente as questões da Nova Biologia (Biotecnologia) e classificar cada uma delas de acordo com o tema específico abordado. Para o desenvolvimento desta etapa utilizou-se como foco os "objetos de conhecimento associados às Matrizes de referência" (BRASIL, 2009) das Ciências da Natureza e suas Tecnologias, especificamente para o que diz respeito à clonagem, célula tronco, tecnologia do DNA recombinante, aplicações da Biotecnologia na produção de alimentos, fármacos e componentes biológicos, aplicações das tecnologias do DNA em aplicações científicas como investigações criminais, determinação de paternidade e identificação de indivíduos, além de aspectos éticos e de sustentabilidade relacionados com a Biotecnologia. Na quarta etapa, os dados foram organizados e interpretados. A metodologia utilizada para a análise dos dados qualitativos foi a análise de conteúdo clássica, usando textos de fluência livre como representante da experiência (RYAN e BERNARD, 2000). Neste caso, uma vez que nas amostras de textos foram selecionadas as questões de Biologia e as questões de Biotecnologia, o próximo passo para a análise de conteúdo foi codificar cada unidade para cada um dos temas da Biotecnologia. A partir deste ponto, os dados puderam ser analisados por técnicas estatísticas. Os dados gerados podem ser classificados como dados discretos com nível de mensuração de razão considerando que os números são finitos de quantidade mensurável e as diferenças e razões são significativas (TRIOLA, 2014). Na quinta etapa foi feita a apresentação dos dados do presente trabalho. A figura 1 representa a sequência de procedimentos utilizados na metodologia e o tempo aproximado em dias para cada procedimento.

Figura 1. Sequência de procedimentos metodológicos. 
Pesquisa no site

do Inep e

gravação das

provas.

(1 dia)
Leitura, organização e identificação das questões de biologia. (4 dias)
Seleção das

questões da

Biotecnologia e

classificação por

tema específico

(4 dias)
Organização e interpretação dos dados e informações. (8 dias)
Apresentação dos dados (10 dias)

Fonte: dados da pesquisa.

O critério de classificação das questões baseou-se nos temas estruturadores propostos nos PCNEM+ de 2007, "Diversidade da Vida" e "Transmissão da Vida, ética e manipulação gênica" (BRASIL, 2007).

As informações geradas são referentes às questões da Nova Biologia abordados de diferentes formas e graus de dificuldade ou profundidade. Apesar das inúmeras possibilidades de análise que as provas do ENEM oferecem, "o analista, no seu trabalho de poda, é considerado como aquele que delimita as unidades de codificação ou as de registro" (BARDIN, 1979, p. 36). Logo, para esta análise foram consideradas questões envolvendo conhecimentos sobre DNA recombinante, enzimas de restrição, eletroforese e PCR, clonagem, transgênicos, melhoramento genético, epigenética, células tronco, teste de paternidade, replicação do DNA, fluxo da informação genética e identificação pelo DNA mitocondrial.

Não foram consideradas, nesta análise as questões de Biotecnologia envolvendo a produção e utilização de vacinas e soros por métodos convencionais, benefícios obtidos através de fermentação como a produção de vinhos, pães e iogurtes e outros recursos Biotecnológicos utilizados antes da manipulação do material genético. As questões não foram analisadas e classificadas de acordo com as habilidades e competências propostas pelas matrizes de referências do ENEM, nem pelo nível de dificuldade. A análise foi feita a partir dos temas propostos e descritos anteriormente.

\section{RESULTADOS E DISCUSSÃO}

Os dados levantados foram tratados e interpretados através de operações estatísticas simples condensando e pondo em relevo as informações obtidas pela análise (BARDIN 1979). 
Em 2009, das 21 questões de biologia, 4 abordaram a Nova Biologia. Em 2010, das 17 questões de Biologia, foram 2 questões da Nova Biologia. Em 2011, das 20 questões de Biologia, 3 questões foram da Nova Biologia. Em 2012, das 17 questões de Biologia, 3 foram da Nova Biologia. Em 2013, das 15 questões de Biologia, 3 foram da Nova Biologia. Em 2014, das 19 questões de Biologia, 2 questões foram sobre a Nova Biologia. Em 2015, das 15 questões de biologia, 1 questão foi sobre a Nova Biologia.

É importante ressaltar que algumas das questões consideradas trazem informações gerais sobre os temas da biotecnologia, porém nem sempre colocam à prova os conhecimentos teóricos sobre o assunto. Ainda assim tais questões foram consideradas pois alunos detentores de conhecimentos básicos sobre a Nova Biologia, teriam melhores condições para resolvê-las.

O gráfico 1 apresenta o número de questões envolvendo Biotecnologia e o número total de questões de Biologia em cada ano partir de 2009 quando foi implantado o Novo ENEM.

Gráfico 1. Análise do número de questões de Biologia e da Nova Biologia entre 2009 e 2015.

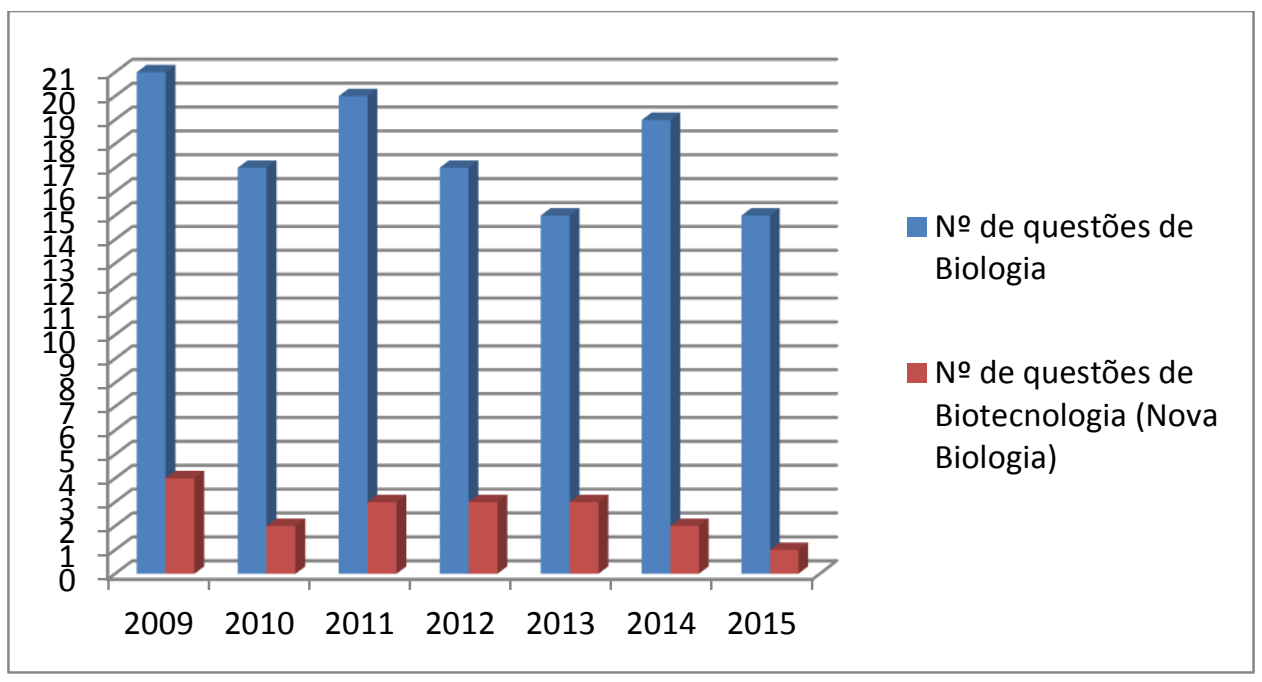

Fonte: dados da pesquisa.

É possível observar que em todos os anos, compreendidos entre 2009 e 2015 foram contempladas questões com temas relacionados à Nova Biologia. O percentual de questões de envolvendo a Nova Biologia nas sete edições do Exame ao longo dos anos de 2009 a 2015 é de $15 \%$ conforme observado no gráfico 2 . 
Gráfico 2. Percentual de questões sobre Biotecnologia dentre as questões de Biologia em todas as edições do novo

ENEM entre os anos de 2009 e 2015.

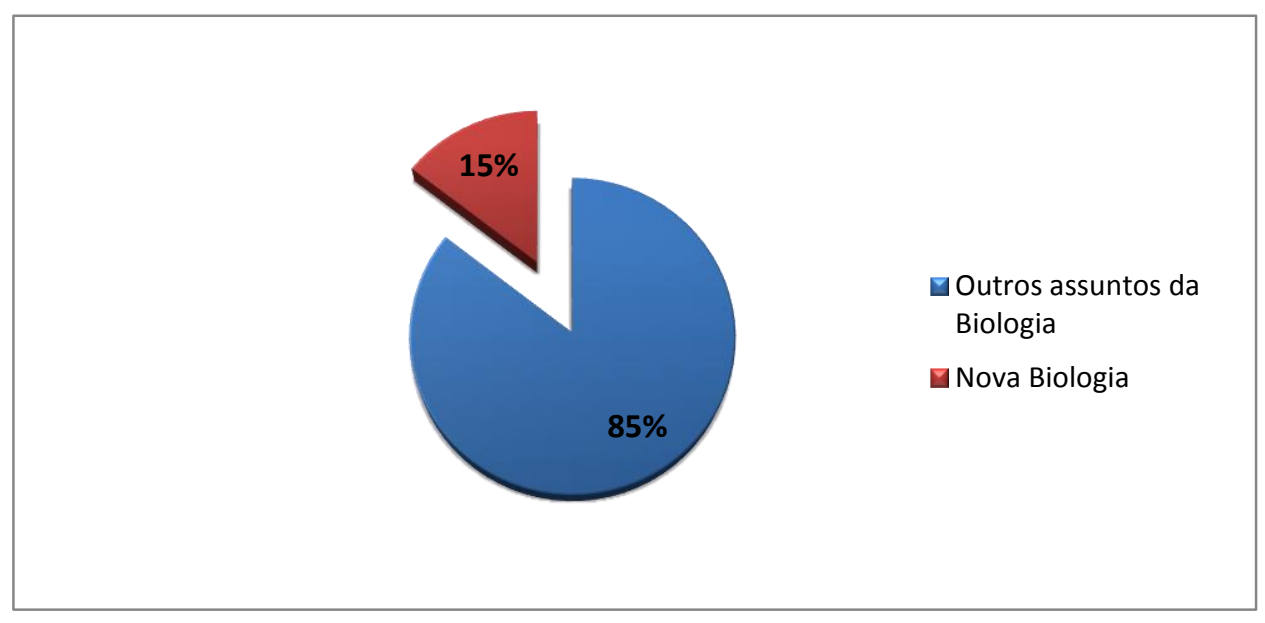

Fonte: dados da pesquisa.

Diante do universo de conteúdos abordados na Biologia do ensino médio que envolve bioquímica, citologia, histologia, genética, fisiologia, microbiologia, botânica, zoologia, ecologia, doenças infecciosas, verminoses, dentre outros temas, pode-se considerar que $15 \%$ de questões contemplando a Biotecnologia, corresponde a um percentual relativamente expressivo.

A análise dos assuntos específicos da Nova Biologia por prova revelou que em 2009, as quatro questões abordaram respectivamente os temas: clonagem, DNA recombinante, fluxo gênico e identificação pelo DNA mitocondrial, representando 19\% da prova de Biologia. Em 2010 as duas questões abordaram respectivamente transgênicos e eletroforese, representando $11,7 \%$ das questões de Biotecnologia na prova de Biologia. Em 2011 três as questões de biotecnologia abordadas foram sobre replicação do DNA, epigenética e DNA recombinante, representando 15\% da prova de Biologia. Em 2012, as três questões sobre a Nova Biologia abordaram melhoramento genético, transgênicos, DNA recombinante e fluxo gênico, observou-se que a questão de número 60, abordou três temas das Biotecnologia, neste ano, 17\% das questões de Biologia foram sobre a Biotecnologia. Em 2013, as três questões da Nova Biologia abordaram transgênicos, DNA recombinante, eletroforese e teste de paternidade e identificação pelo DNA mitocondrial, representando 20\% da prova de Biologia. Em 2014, as duas questões da Nova Biologia abordaram transgênicos e célula tronco, representando 10,5\% da prova de Biologia. Em 2015 uma questão abordou o assunto DNA recombinante. Os dados estão representados na tabela 1.

Tabela 1. Distribuição das questões sobre a Nova Biologia ao longo dos sete anos do Novo ENEM. 


\begin{tabular}{|c|c|c|c|c|c|}
\hline ANO & $\begin{array}{c}\text { No DE } \\
\text { QUESTÕES } \\
\text { DA NOVA } \\
\text { BIOLOGIA }\end{array}$ & $\begin{array}{c}\text { NNo DE } \\
\text { QUESTÕES } \\
\text { BIOLOGIA }\end{array}$ & $\begin{array}{l}\text { PERCENTUAL DE } \\
\text { QUESTÕES DA } \\
\text { NOVA BIOLOGIA }\end{array}$ & $\begin{array}{c}\text { NN DAS } \\
\text { QUESTÕES } \\
\text { NAS } \\
\text { PROVAS }\end{array}$ & ASSUNTO \\
\hline 2009 & 4 & 21 & $19 \%$ & $\begin{array}{c}4 \\
6 \\
16 \\
40\end{array}$ & $\begin{array}{l}\text { Clonagem } \\
\text { DNA recombinante } \\
\text { Fluxo gênico } \\
\text { DNA mitocondrial }\end{array}$ \\
\hline 2010 & 2 & 17 & $11,7 \%$ & $\begin{array}{l}76 \\
90\end{array}$ & $\begin{array}{l}\text { Transgênicos } \\
\text { Eletroforese }\end{array}$ \\
\hline 2011 & 3 & 20 & $15 \%$ & $\begin{array}{l}62 \\
66 \\
67\end{array}$ & $\begin{array}{l}\text { Replicação do DNA } \\
\text { Epigenética } \\
\text { DNA recombinante }\end{array}$ \\
\hline 2012 & 3 & 17 & $17 \%$ & $\begin{array}{l}47 \\
60 \\
63\end{array}$ & $\begin{array}{l}\text { Melhoramento genético } \\
\text { DNA recombinante, } \\
\text { Transgênicos, } \\
\text { Fluxo gênico } \\
\text { Fluxo gênico }\end{array}$ \\
\hline 2013 & 3 & 15 & $20 \%$ & $\begin{array}{l}50 \\
73 \\
75\end{array}$ & $\begin{array}{l}\text { Transgênicos, } \\
\text { DNA recombinante } \\
\text { Eletroforese, } \\
\text { Teste de paternidade } \\
\text { DNA mitocondrial }\end{array}$ \\
\hline 2014 & 2 & 19 & $10,5 \%$ & $\begin{array}{l}48 \\
51\end{array}$ & $\begin{array}{l}\text { Transgênicos } \\
\text { Célula tronco }\end{array}$ \\
\hline 2015 & 1 & 15 & $6,6 \%$ & 54 & DNA recombinante \\
\hline
\end{tabular}

Os temas da Nova Biologia abordados nas seis edições do Novo ENEM foram clonagem, DNA recombinante, fluxo da informação genética, identificação de indivíduos pelo DNA mitocondrial, eletroforese, teste de paternidade, transgênicos, replicação do DNA, epigenética, melhoramento genético e células tronco. Algumas questões contemplam mais de um assunto da Biotecnologia dentre os assuntos abordados.

De acordo com o gráfico 3, é possível observar que há um predomínio de questões referentes ao DNA recombinante com 23\%, seguido do assunto Transgênicos com $18 \%$ das questões de Biologia que envolvem a Nova Biologia ao longo das sete edições do Novo ENEM. 14\% das questões contemplam o fluxo da informação genética. Identificação de indivíduos através de DNA mitocondrial aparece em $9 \%$ das questões e eletroforese também em $9 \%$ das questões. Outros 
temas como teste de paternidade, célula tronco e melhoramento genético, clonagem, epigenética e replicação do DNA aparecem em 4 a 5\% das questões de Biotecnologia nas sete edições do Novo ENEM.

Gráfico 3. Distribuição das questões relacionadas à Biotecnologia (Nova Biologia) por assunto nas seis edições do Novo ENEM de 2009 a 2015.

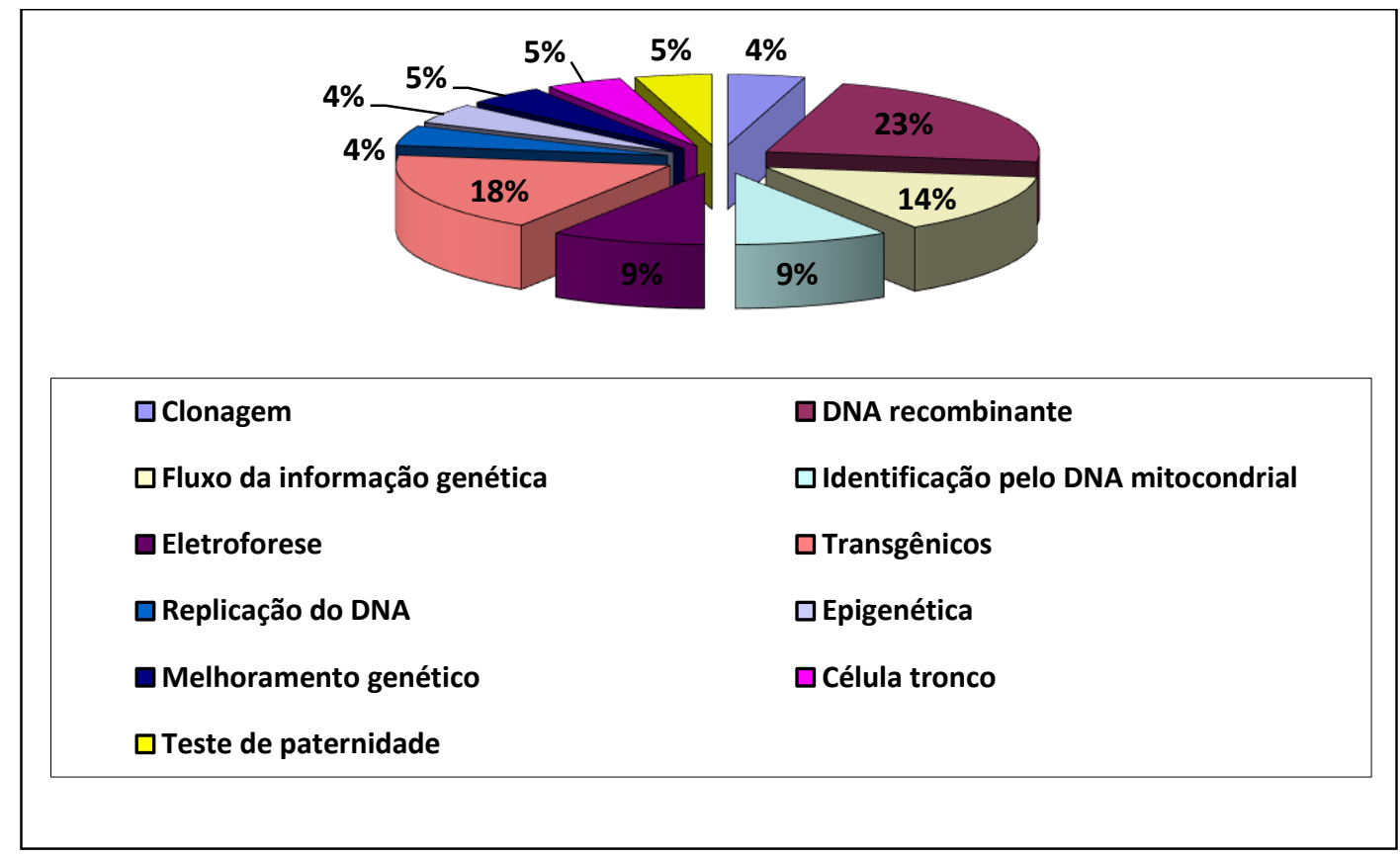

Fonte: dados da pesquisa.

Segundo Xavier et al (2005), temas de maior destaque na mídia como por exemplo transgênicos, clonagem, células tronco e teste de paternidade, são os mais abordados pelos professores. Porém de acordo com os resultados obtidos, dos temas comumente explorados pela mídia, apenas transgênicos se destaca nas edições pesquisadas do exame, com uma frequência de $18 \%$ das questões. Os temas relacionados à clonagem e células tronco e teste de paternidade são abordados com uma frequência de 4 a 5\%, ou seja, relativamente baixa. Por outro lado, há um destaque no número de questões relacionadas aos temas pouco abordados pela mídia como, "DNA recombinante" representando $23 \%$ das questões, seguido dos temas "Fluxo da informação genética, 14\%. Eletroforese e identificação por DNA mitocondrial com $9 \%$ das questões cada um. Estes dados sugerem que o Novo ENEM não segue a lógica midiática sobre os temas da Nova Biologia.

O Exame Nacional do Ensino Médio sinaliza para a necessidade de uma abordagem baseada na fundamentação em diversos temas da Nova Biologia, conforme documentos oficiais como os PCN's, 
e os PCN's+ já orientam. Alunos com melhor embasamento nas diversas áreas da Biotecnologia, podem alcançar melhores resultados na conclusão do ensino médio, e ainda desenvolver algum senso crítico a respeito de tais temas, o que confronta o estigma que diz que "a sociedade desinformada não tem base para questionar os benefícios e malefícios da Biotecnologia, ficando a mercê da forma como a mídia trata essa questão" (GOULART, MAIA, 2012, p. 2).

Os quadros 1, 2, 3 e 4 apresentam algumas questões que abordam a Nova Biologia no ENEM.

Quadro 1. Questão no 60 da prova de Ciências da Natureza, ENEM 2012.

O milho transgênico é produzido a partir da manipulação do milho original, com a transferência, para este, de um gene de interesse retirado de outro organismo de espécie diferente.

A característica de interesse será manifestada em decorrência
a) do incremento do DNA a partir da duplicação do gene transferido.
b) da transcrição do RNA transportador a partir do gene transferido.
c) da expressão de proteínas sintetizadas a partir do DNA não hibridizado.
d) da síntese de carboidratos a partir da ativação do DNA do milho original.
e) da tradução do RNA mensageiro sintetizado a partir do DNA recombinante.

Fonte: INEP, 2012.

A questão 60 do ENEM 2012 (quadro 1), aparentemente simples, envolve conceitos de transgênicos, fluxo gênico e DNA recombinante. A abordagem sobre transgênicos ocorre quando menciona a transferência do material genético, logo no enunciado, Fluxo gênico é mencionado quando no distrator da letra $(E)$, correspondente ao gabarito da questão, menciona que a manifestação da característica de interesse ocorrerá em decorrência da tradução do m-RNA sintetizado a partir do DNA recombinante. A compreensão termo DNA recombinante, se dá principalmente durante o estudo da Tecnologia do DNA recombinante. Segundo Sapatini (2014), a questão no 60 de 2012 aborda a competência 5 "Entender métodos e procedimentos próprios das ciências naturais e aplicá-los em diferentes contextos", da Matriz de Referência do Novo ENEM. 
Quadro 2. Questão no 50 da prova de Ciências da Natureza, ENEM 2013.

A estratégia de obtenção de plantas transgênicas pela inserção de transgenes em cloroplastos, em substituição à metodologia clássica de inserção do transgene no núcleo da célula hospedeira, resultou no aumento quantitativo da produção de proteínas recombinantes com diversas finalidades biotecnológicas. O mesmo tipo de estratégia poderia ser utilizada para produzir proteínas recombinantes em células de organismos eucarióticos não fotossintetizantes, como as leveduras, que são usadas para produção comercial de várias proteínas recombinantes e que podem ser cultivadas em grandes fermentadores.

Considerando a estratégia metodológica descrita, qual organela celular poderia ser utilizada para inserção de transgenes em leveduras?

a) Lisossomo.

b) Mitocôndria.

c) Peroxissomo.

d) Complexo golgiense.

e) Retículo endoplasmático.

Fonte: INEP, 2013.

A questão 50 do ENEM 2013 (quadro 2) aborda a temática da transgenia quando no enunciado cita plantas transgênicas e inserção de transgenes. Além do mais o termo "proteínas recombinantes" arremete o leitor à tecnologia do DNA recombinante, cujas técnicas são necessárias para a obtenção dos referidos produtos. $O$ gabarito $B$, mitocôndria, corresponde à única organela dentre as outras alternativas a possuir DNA, neste seriam introduzidos através da tecnologia do DNA recombinante os ditos transgenes.

Quadro 3: Questão no 73 da prova de Ciências da Natureza, ENEM 2013 
Cinco casais alegavam ser os pais de um bebê. A confirmação da paternidade foi obtida pelo exame de DNA. O resultado do teste está esquematizado na figura, em que cada casal apresenta um padrão com duas bandas de DNA (faixas, uma para o suposto pai e outra para a suposta mãe), comparadas à do bebê.

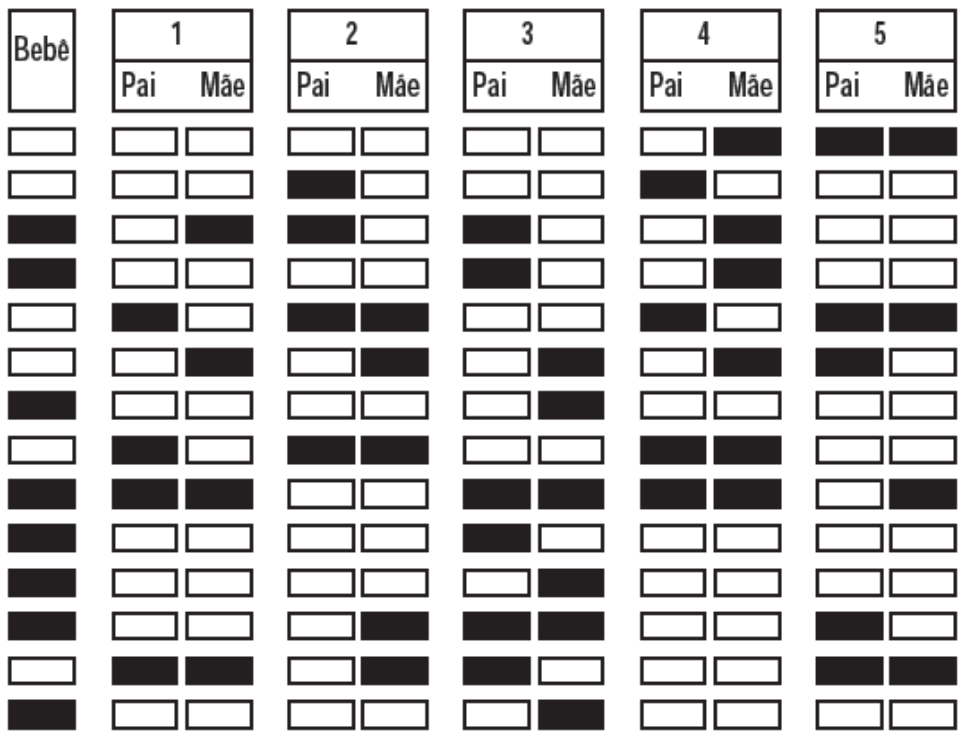

Que casal pode ser considerado como pais biológicos do bebê?
a) 1
b) 2
c) 3
d) 4
e) 5

Fonte: INEP, 2013.

A questão no 73 do ENEM 2013 (quadro 3) envolve o teste de paternidade e técnica de eletroforese. As questões do ENEM são estruturadas, com gráficos, tabelas, charges ou figuras que contextualizam o conteúdo de maneira interessante (SAPATINI 2014). A questão citada, testa a habilidade H17 "Relacionar informações em diferentes formas de linguagem e representação usadas nas ciências físicas, químicas ou biológicas, como texto discursivo, gráficos, tabelas, relações matemáticas ou linguagem simbólica" da Matriz de referência do Novo ENEM 2013. Embora não seja uma questão que se possa classificar como difícil, é possível sugerir que alunos com conhecimentos básicos sobre eletroforese e habilidade para interpretar a forma de linguagem utilizada, teriam menores dificuldades para sua resolução. 
Quadro 4. Questão no 90 da prova de Ciências da Natureza, ENEM 2010

Três dos quatro tipos de testes atualmente empregados para a detecção de príons patogênicos, em tecidos cerebrais do gado morto, são mostrados nas figuras a seguir. Uma vez identificados um animal morto infectado, funcionários das agências de saúde pública e fazendeiros podem removê-lo do suprimento alimentar ou rastrear os alimentos infectados que o animal possa ter consumido.

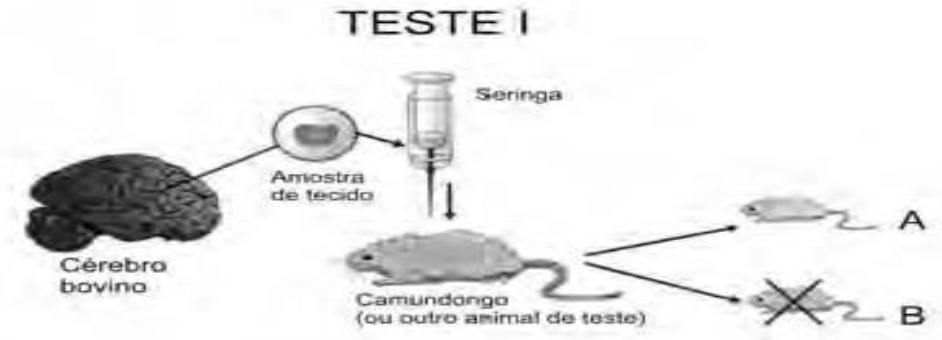

\section{TESTE ॥}

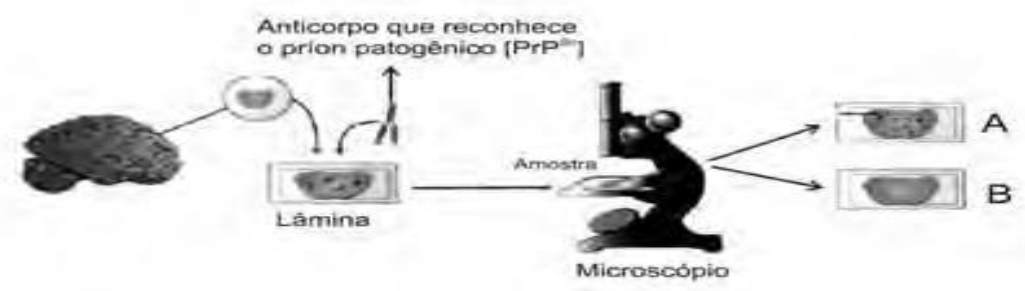

TESTE III

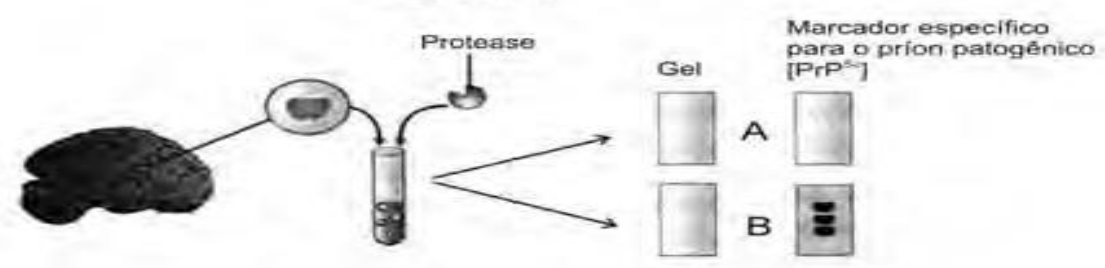

Analisando os testes I, II e III, para a detecção de príons patogênicos, identifique as condições em que os resultados foram positivos para a presença de príons nos três testes:

a) Animal A, Lâmina $B$, Gel $A$

b) Animal A, Lâmina A, Gel B

c) Animal B, Lâmina A, Gel B

d) Animal B, Lâmina B, Gel A

e) Animal A, Lâmina B, Gel B

Fonte: INEP, 2010.

Na questão 90 do ENEM 2010 (quadro 4), especificamente o teste III refere-se a um mecanismo de separação de moléculas em que se utiliza a técnica da eletroforese. Os termos "marcador e gel" e a representação das bandas no gel, exigem conhecimento mínimo da técnica da eletroforese para que $o$ aluno tenha segurança para sua resolução. 


\section{CONSIDERAÇÕES FINAIS}

Os temas relacionados à Biotecnologia têm sido frequentemente abordados no Novo ENEM. Todas as versões do exame, entre 2009 e 2015, abordaram pelo menos uma questão relacionada à Biotecnologia. Ao todo este tema representa $15 \%$ das questões de Biologia contempladas no período. Este fato reforça a tese de que o Ministério da Educação tende a incluir de vez a Biotecnologia no currículo do ensino básico. Estes dados corroboram com documentos oficiais que primam pelo desenvolvimento de habilidades que contemplem os diversos temas da Biotecnologia para a formação de uma sociedade crítica e inserida nas discussões relacionadas ao tema.

Os temas da Biotecnologia mais abordados ao longo das edições de 2009 a 2015 do ENEM são Tecnologia do DNA recombinante, Transgênicos, Fluxo gênico, seguido de DNA mitocondrial e eletroforese. Com menor frequência aparecem temas como teste de paternidade, células tronco, melhoramento genético. Estes resultados apontam para a necessidade de que temas variados sobre a Biotecnologia sejam abordados com compromisso e eficácia durante o ensino médio e que não necessariamente os temas mais frequentes na mídia são os mais contemplados no Exame.

\section{REFERÊNCIAS}

Agostinho, L. A. PARAdelA, E. R. PAivA, C. L. A. FigueIREDO, A. L. Construção de sistema Multiplex utilizando cinco marcadores genéticos do tipo mini-STR (short-amplicons) para identificação humana por análise de DNA. Revista científica Faminas. Muriaé, v.7, n.3, p. 12 - 41, set.-dez. de 2011.

ANDRIOLA, Wagner B. Doze motivos favoráveis à adoção do Exame Nacional do Ensino Médio (ENEM) pelas Instituições Federais de Ensino Superior (IFES). Ensaio: aval. pol. públ. Educ., Rio de Janeiro, v. 19, n. 70, p. 107-126, jan./mar. 2011.

BARDIN, L. Análise de conteúdo. São Paulo: Edições 70, 1979. 225p.

BRASIL. PCN + Ensino Médio: Orientações Educacionais Complementares aos Parâmetros Curriculares Nacionais, Ciências da Natureza, Matemática e suas Tecnologias, 2007. Disponível em: <http://portal.mec.gov.br/seb/arquivos/pdf/CienciasNatureza.pdf>. Acesso em: 10 out. 2016.

Ministério da Educação. Instituto Nacional de Estudos e Pesquisas Educacionais Anísio Teixeira. ENEM: documento Básico. $\quad$ Brasília. $2012 . \quad$ Disponível <http://download.inep.gov.br/educacao_basica/enem/provas/2012/caderno_enem2012_sab_amarelo.pdf>. Acesso em: 22 mar. 2016.

- _ _ _ _ ENEM: documento Básico. Brasília. 2013. Disponível em: <http://download.inep.gov.br/educacao_basica/enem/provas/2013/caderno_enem2013_sab_amarelo.pdf >. Acesso em: 29 mar. 2016.

Matriz de Referência para o ENEM 2009. Brasília, Distrito Federal, 2009a. 26p.

. Ministério da Educação e dos Desportos. Parâmetros curriculares nacionais: ensino médio. Parte III - Ciências da Natureza, Matemática e suas Tecnologias. Brasília, Distrito Federal, 2000. 58p. 
BOSSOLAN, N. R. S.; SANTOS, N. F.; MORENO, R. de R.; BELTRAMINI, L. M. O centro de biotecnologia molecular estrutural: aplicação de recursos didáticos desenvolvidos junto ao ensino médio. Ciencia e Cultura. 2005, vol.57, n.4, pp. 41-42. ISSN 2317-6660.

GOULART, A. O. F. MAIA, E. D. Biotecnologia no século XXI: um caso de letramento científico. Em: III SIMPÓSIO Nacional de Ensino de Ciência e Tecnologia. Anais ... Ponta Grossa-PR, 2012.

LOPES, A. C. e LÓPEZ, S. B. A performatividade nas políticas de currículo: o caso do ENEM. Educação em Revista, Belo Horizonte, v.26, n.01, p.89-110, abr. 2010.

LORETO, E. L. S. e SEPEL, L. M. N. (2003) Atividades Experimentais e Didáticas de Biologia Molecular e Celular. 2a Ed., Sociedade Brasileira de Genética. Ribeirão Preto. SP. 81p.

OLIVEIRA, S. D. LEITE, A. G. HOSSY, B. H. ANGELI, R. Análise de patentes envolvendo plantas transgênicas mais tolerantes a estresse abiótico, Anais SIMTEC - ISSN: 2318-3403. Aracaju/SE - 25 a 27/09/ 2013. Vol. 1/n. 1/ p. 376-389

REIS, P. R. O “admirável mundo novo” em discussão. Ministério da Educação, 1ạ edição, Lisboa, 70p, 2003.

RYAN, G. W. BERNARD, H. R. Data management and analysis methods. In: Denzin, N. Lincolln, Y. Handbook of Qualitative Research. 2nd Edition, Sage, 2000, p. 769-802

SANTOS, J. M. C. T. Exame Nacional do Ensino Médio: entre a regulação da qualidade do Ensino Médio e o vestibular. Educar em Revista, Curitiba, Brasil, n. 40, p. 195-205, abr./jun. 2011. Editora UFPR

SAPATINI, J. R. Categorização e análise das questões de Biologia do ENEM. 2014. 43 f. Monografia (Especialização em Ensino de Ciências). Universidade Tecnológica Federal do Paraná, Professor Dr. Fernando Periotto Medianeira, 2014

TERRA, A. P. S. VERGARA, M. L. S. GOMES, R. A. S. PEREIRA, C. L. L. SIMPSON, A. J.G. CABALLERO. O. L. Monitoramento de pacientes com AIDS para o desenvolvimento de doença por citomegalovírus (CMV) usando-se PCR multiplex. Revista da Sociedade Brasileira de Medicina Tropical, v. 6, n. 33, p.583-589, nov-dez, 2000

TRIOLA, M. F. Introdução a Estatística. Rio de Janeiro: Livros Técnicos e Científicos 10. Ed. 2014. 707p.

XAVIER, M.C.; FREIRE A. S.; MORAES, M.O. A introdução dos conceitos de Biologia Molecular e Biotecnologia no Ensino de Genética no Nível Médio: há espaço para a nova Biologia? Em: 5 ENCONTRO Nacional de Pesquisa em Educação em Ciências. Atas ... Bauru: Abrapec, 2005. 